\title{
Study of the Psychological Aspect of Children with Internet Addiction
} Amira M Mohammed ${ }^{1}$, Mohammed Y Abd El-Hameed ${ }^{* 1}$, Islam S Mohammed ${ }^{2}$

${ }^{1}$ Department of Pediatric, ${ }^{2}$ Department of Neuropsychiatric, Faculty of Medicine, Al-Azhar University (Assiut)

*Corresponding author: Mohammed Y Abd El-Hameed, Email: mohyah_7582@yahoo.com, Mobile: (+20)01021165886 - +201000897884

\begin{abstract}
Back ground: Internet addiction is defined as an impulse control disorder that does not involve the use of an intoxicating drug and is very similar to pathological gambling. Internet addiction is defined as a maladaptive use of the Internet that can lead to social and functional impairment.

Objective: To determine the risk factors of internet addiction $\&$ the relation between internet addiction $\&$ the effects on the psychological aspects of the internet-addicted children.

Subject and methods: This study included 80 students, 40 cases aged 6-16 years. Another 40 of matched children regarding age (6-16 years) and sex were included in the study as control group.

Results: As regards the score results of the Hamilton depression rating scale: of the patient group $32.5 \%$ ( $\mathrm{n}=13$ ) showed mild depression, 50\% $(n=20)$ showed moderate depression and $17 \%(n=7)$ showed severe depression, while $100 \%(\mathrm{n}=40)$ of the control group showed no depression symptoms. As regards the score results of the Hamilton anxiety rating scale: of the patient group 37.5\% $(n=15)$ showed mild anxiety, $60 \%(n=24)$ showed moderate anxiety and $2.5 \%(n=1)$ showed severe anxiety, while $100 \%(n=40)$ of the control group show no anxiety symptoms

Conclusions: No doubt that the internet is very important in our life. Our study showed strong association between positive family history of excessive internet use and the internet addiction among children of those families. Our study showed a significant association between internet addiction and depression and anxiety. Often there was a vicious cycle of depression or anxiety resulting from internet addiction which further begets depression or anxiety.
\end{abstract}

Keywords: internet addiction disorder, IAD, pathological internet use, PIU, problematic Internet use, PIU, Internet dependency.

\section{INTRODUCTION}

The internet is considered the most effective tool in all areas of science, business, education, culture, and politics. The Internet was established in the early 1960s and subsequently became a mainstream communication vehicle (1). "Addiction" comes from the Latin word "addicere" which means "bound to" or "enslaved by" (2). In 1996, the concept of Internet Addiction Disorder (IAD) emerged for the first time ${ }^{(3)}$. Various terms have been used to name the condition, including compulsive computer use, internet dependency ${ }^{(4)}$, pathological internet use (PIU), virtual addiction and internet addiction disorder ${ }^{(5)}$.

Internet addiction is defined as the difficulty controlling ones impulses and the inability to disconnect from internet ${ }^{(6)}$. Beard and Wolf ${ }^{(7)}$, defined IA as "an excessive internet use causing psychological, physical and personal issues". Young ${ }^{(8)}$, had identified seven reasons for the IAD such as marital discontent, work related stress, financial problems, insecurity, anxiety, struggle in life, and limited social life.

Several researchers suggested that problematic internet use stems from unmet real-life needs and that it is a way to relieve the problems encountered in daily life ${ }^{(8,9)}$. The internet offers a highly accessible and immediate medium for users to satisfy such unmet needs ${ }^{(10)}$. With reference to

self-determination theory, needs can be grouped into three major types; relatedness, competence, and autonomy ${ }^{(11)}$.

Estimates vary from country to country and from study to study. It has been estimated that $1 \%$ $18 \%$ of adolescents have PIU in both Western and Eastern societies ${ }^{(\mathbf{1 2})}$. More specifically, about $1 \%$ $2 \%$ of Italian students have moderate to severe PIU, $1 \%-12 \%$ of children and adolescents in Middle Eastern countries and 2\%-18\% of children and adolescents in Asian countries appear to have PIU. Small scale studies in Korea and China revealed that around 2\% $(210,000)$ of South Korean children aged 6 to19 years have PIU and many may require treatment, while around 10 million adolescent internet users in China may meet criteria for Internet addiction ${ }^{(12)}$.

A study was performed on 587 medical students of Sohag university, of whom 276 (47\%) were from the Faculty of Medicine, 197 (33.6\%) and 114 (19.4\%) were from Faculties of Pharmacy and Nursing, respectively. Results showed that $47.7 \%$ of the students were internet addicts ${ }^{(13)}$. A crosssectional survey included a total of 2196 undergraduate students from ten colleges at Zagazig University. The mean age of the participants was $20.7 \pm 2.1$ and females represented almost $70 \%$ of 
the sample. The prevalence of internet addiction was $41.5 \%(\mathrm{n}=912)$ among the university students ${ }^{(\mathbf{1 4})}$.

The typical features of internet addiction in terms of Voiskunskiy ${ }^{(15)}$ are the inability and active unwillingness to be distracted from the internet even for a short period of time; annoyance and irritation occurring at forced distractions; the desire to spend more time working in the internet; the motive to spend more money on the provision of work in the internet; the readiness to lie to friends and family, downplaying the duration of work in the internet and the ability and tendency to forget about the domestic chores, education, important personal and business meetings when browsing the internet ${ }^{(15)}$.

\section{AIM OF THE STUDY}

Aim of this study was to determine the risk factors of internet addiction and the relation between internet addiction \& the effects on the psychological aspects of the internet addicted children.

\section{SUBJECT AND METHOD}

A cross sectional study was conducted in the city of Sohag, from December 2016 to February 2019.

\section{Patients:}

This study included 80 students, 40 students as the patient group and 40 students [of matched age (6-16 years) and sex] as the control group, with free general \& neurological examinations. This study was conducted in the primary, prepatory and secondary schools of the city of Sohag. We defined the time spent on the internet as follow: less than 5 hours per day is considered as mild internet user, more than 5 hours per day is considered excessive internet user.

\section{Inclusion criteria:}

- Children with internet addiction in the first visit to the clinic, aging from 6 to 18 years.

- Any child with past history of internet addiction.

- A consent was taken from parents or caregiver of the students.

- No present history of prominent co-morbid neurological or psychiatric conditions.

\section{Exclusion criteria:}

- Any children below 6 years or above 16 years of age.

- Children with chronic debilitating disease.

- Any child with insufficient data.

- Refusal of the child or the parents to be involved in the study.

- Any child treated from prominent co-morbid psychiatric or neurological condition.

\section{Ethical consideration:}

- The study was approved by the Ethics Board of Al-Azhar University.
- A consent was taken from the parents or caregiver before including their child/ren in the study.

- Aim of the study was explained to the parents of the child.

- The privacy of the study data was assured to the parents or caregiver as it will be used only in medical research purposes.

\section{Method:}

This study was performed using a questionnaire, the modified Young's questionnaire and "the proposed internet addiction diagnostic criteria Questionnaire", to determine the degree of internet addiction among those students (7). We defined the time spent on the internet as follow: less than 5 hours per day is considered as mild internet user, more than 5 hours per day is considered excessive internet user. Then, children who proved to be internet addicted were screened using the Hamilton Anxiety Rating Scale (HAM-A) (16) \& Hamilton Depression Rating Scale (HAM-D) ${ }^{(17)}$ to determine the degree of anxiety \& depression among those children.

The following data were recorded from the parents of the children:

- Demographic data (Age, sex and consanguinity).

- Family history of excessive internet use.

- Parental education, occupation and socioeconomic status.

- Marital status of mother.

- Developmental and medical history of the children.

\section{Statistical analysis}

Recorded data were analyzed using the statistical package for social sciences, version 20.0 (SPSS Inc., Chicago, Illinois, USA). Quantitative data were expressed as mean \pm standard deviation (SD). Qualitative data were expressed as frequency and percentage. The following tests were used:

- Independent-samples t-test of significance was used when comparing between two means.

- Chi-square $\left(\mathrm{x}^{2}\right)$ test of significance was used in order to compare proportions between two qualitative parameters.

- The confidence interval was set to $95 \%$ and the margin of error accepted was set to $5 \%$. The pvalue was considered significant as the following:

- Probability (P-value)

$\mathrm{P}$-value $<0.05$ was considered significant

P-value $<0.001$ was considered as highly significant.

- $\quad$ P-value >0.05 was considered insignificant. 
RESULTS

Table (1): Descriptive data of the study groups

\begin{tabular}{|c|c|c|c|c|c|c|c|}
\hline & \multicolumn{2}{|c|}{$\begin{array}{l}\text { Patient group } \\
(\mathrm{No}=40)\end{array}$} & \multicolumn{2}{|c|}{$\begin{array}{c}\text { Control group } \\
(\mathrm{No}=40)\end{array}$} & \multicolumn{2}{|c|}{ Chi square test } \\
\hline & & No & $\%$ & No & $\%$ & $\mathrm{X}^{2}$ & $P$ value \\
\hline \multirow{2}{*}{ Sex } & Male & 28 & $70.0 \%$ & 25 & $62.5 \%$ & \multirow{2}{*}{0.503} & \multirow{2}{*}{0.478} \\
\hline & Female & 12 & $30.0 \%$ & 15 & $37.5 \%$ & & \\
\hline \multirow{4}{*}{ AGE (Years) } & From 6 to 9 years & 13 & $32.5 \%$ & 12 & $30.0 \%$ & \multirow{3}{*}{0.586} & \multirow{3}{*}{0.746} \\
\hline & From 10 to 13 years & 9 & $22.5 \%$ & 12 & $30.0 \%$ & & \\
\hline & From 14 to 16 years & 18 & $45.0 \%$ & 16 & $40.0 \%$ & & \\
\hline & Mean \pm SD & 11.93 & 3.08 & 11.85 & 3.10 & -0.109 & 0.914 \\
\hline \multirow{2}{*}{ Consanguinity } & Positive & 8 & $20.0 \%$ & 0 & $0.0 \%$ & \multirow{2}{*}{8.889} & \multirow{2}{*}{0.003} \\
\hline & Negative & 32 & $80.0 \%$ & 40 & $100.0 \%$ & & \\
\hline
\end{tabular}

This table showed that there was no statistically significant difference in demographic data regarding studied groups.

Table (2): Comparison between patient group \& control group as regards HAM-A score

\begin{tabular}{|c|c|c|c|c|c|c|c|}
\hline & & \multicolumn{2}{|c|}{$\begin{array}{l}\text { Patient group } \\
(\mathrm{No}=40)\end{array}$} & \multicolumn{2}{|c|}{$\begin{array}{c}\text { Control group } \\
(\mathrm{No}=40)\end{array}$} & \multicolumn{2}{|c|}{ Chi square test } \\
\hline & & No & $\%$ & No & $\%$ & $\mathrm{X}^{2}$ & $\mathrm{P}$ value \\
\hline \multirow{5}{*}{ HAM-A score } & Normal & 0 & $0.0 \%$ & 38 & $95.0 \%$ & \multirow{4}{*}{80.000} & \multirow{4}{*}{$<0.001$} \\
\hline & Mild anxiety & 15 & $37.5 \%$ & 2 & $5.0 \%$ & & \\
\hline & Moderate anxiety & 24 & $60.0 \%$ & 0 & $0.0 \%$ & & \\
\hline & Severe anxiety & 1 & $2.5 \%$ & 0 & $0.0 \%$ & & \\
\hline & Mean \pm SD & \multicolumn{2}{|c|}{$18.30 \pm 3.14$} & \multicolumn{2}{|c|}{$6.83 \pm 1.41$} & 21.082 & $<0.001$ \\
\hline
\end{tabular}

This table showed that there was statistically significant increase in patient group in comparison to control group with HAM-A score.

Table (3): Comparison between patient group \& control group as regards HAM-D score

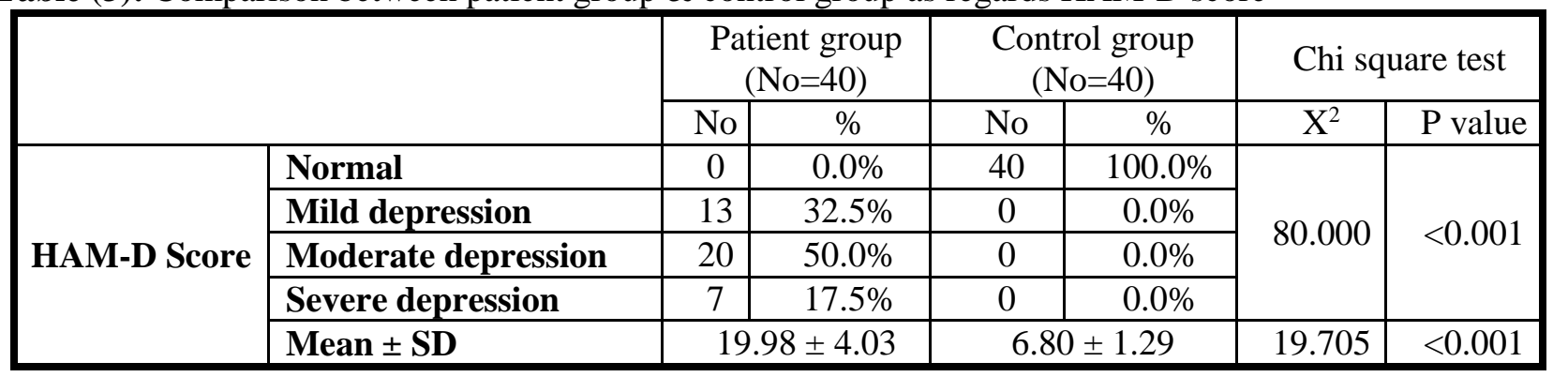

This table showed that there was statistically significant increase in patient group in comparison to control group with HAM-D score.

Table (3): Comparison between patient group \& control group as regards anxiety and depression

\begin{tabular}{|c|c|c|c|c|c|c|c|}
\hline & & \multicolumn{2}{|c|}{$\begin{array}{l}\text { Patient group } \\
(\mathrm{No}=40)\end{array}$} & \multicolumn{2}{|c|}{$\begin{array}{c}\text { Control group } \\
(\mathrm{No}=40)\end{array}$} & \multicolumn{2}{|c|}{ Chi square test } \\
\hline & & No & $\%$ & No & $\%$ & $\mathrm{X}^{2}$ & $\mathrm{P}$ value \\
\hline \multirow{4}{*}{ Anxiety } & One & 0 & $0.0 \%$ & 40 & $100.0 \%$ & \multirow{4}{*}{80.000} & \multirow{4}{*}{$<0.001$} \\
\hline & Two & 15 & $37.5 \%$ & 0 & $0.0 \%$ & & \\
\hline & Three & 24 & $60.0 \%$ & 0 & $0.0 \%$ & & \\
\hline & Four & 1 & $2.5 \%$ & 0 & $0.0 \%$ & & \\
\hline \multirow{4}{*}{ Depression } & One & 0 & $0.0 \%$ & 40 & $100.0 \%$ & \multirow{4}{*}{80.000} & \multirow{4}{*}{$<0.001$} \\
\hline & Two & 13 & $32.5 \%$ & 0 & $0.0 \%$ & & \\
\hline & Three & 20 & $50.0 \%$ & 0 & $0.0 \%$ & & \\
\hline & Four & 7 & $17.5 \%$ & 0 & $0.0 \%$ & & \\
\hline
\end{tabular}

This table showed that there was statistically significant increase in patient group in comparison to control group with anxiety and depression. 
Table (4): Comparison between patient group \& control group as regards school performance and family history of excessive internet use

\begin{tabular}{|c|c|c|c|c|c|c|c|}
\hline & & \multicolumn{2}{|c|}{$\begin{array}{l}\text { Patient group } \\
(\mathrm{No}=40)\end{array}$} & \multicolumn{2}{|c|}{$\begin{array}{l}\text { Control group } \\
(\mathrm{No}=40)\end{array}$} & \multicolumn{2}{|c|}{ Chi square test } \\
\hline & & No & $\%$ & No & $\%$ & $\mathrm{X}^{2}$ & $P$ value \\
\hline \multirow{3}{*}{ School performance } & Good & 15 & $37.5 \%$ & 0 & $0.0 \%$ & \multirow{3}{*}{34.348} & \multirow{3}{*}{0.001} \\
\hline & Very good & 25 & $62.5 \%$ & 21 & $52.5 \%$ & & \\
\hline & Excellent & 0 & $0.0 \%$ & 19 & $47.5 \%$ & & \\
\hline \multirow{2}{*}{$\begin{array}{c}\text { Family history } \\
\text { of excessive internet use }\end{array}$} & Positive & 40 & $100.0 \%$ & 7 & $17.5 \%$ & \multirow{2}{*}{56.170} & \multirow{2}{*}{0.001} \\
\hline & Negative & 0 & $0.0 \%$ & 33 & $82.5 \%$ & & \\
\hline
\end{tabular}

This table showed that there was statistically significant difference in school performance and family history of excessive internet use regarding patient group.

Table (6): Comparison between patient group \& control group as regards time spent on the internet and type of activity on the internet

\begin{tabular}{|c|c|c|c|c|c|c|c|}
\hline & & \multicolumn{2}{|c|}{$\begin{array}{l}\text { Patient group } \\
(\mathrm{No}=40)\end{array}$} & \multicolumn{2}{|c|}{$\begin{array}{l}\text { Control group } \\
(\mathrm{No}=40)\end{array}$} & \multicolumn{2}{|c|}{ Chi square test } \\
\hline & & No & $\%$ & $\mathrm{No}$ & $\%$ & $\mathrm{X}^{2}$ & $\mathrm{P}$ value \\
\hline \multirow{3}{*}{$\begin{array}{c}\text { Time spent on } \\
\text { the internet }\end{array}$} & 5 - 7 hours/day & 18 & $45.0 \%$ & 7 & $17.5 \%$ & \multirow{3}{*}{59.840} & \multirow{3}{*}{0.001} \\
\hline & 8 - 10 hours/day & 22 & $55.0 \%$ & 0 & $0.0 \%$ & & \\
\hline & Less than 5 hours/day & 0 & $0.0 \%$ & 33 & $82.5 \%$ & & \\
\hline \multirow{6}{*}{$\begin{array}{c}\text { Type of } \\
\text { Activity on the } \\
\text { internet }\end{array}$} & Internet gaming & 16 & $40.0 \%$ & 14 & $35.0 \%$ & \multirow{6}{*}{17.552} & \multirow{6}{*}{0.004} \\
\hline & Watching cartoon & 4 & $10.0 \%$ & 7 & $17.5 \%$ & & \\
\hline & $\begin{array}{l}\text { Watching videos } \\
\text { (movies-others) }\end{array}$ & 5 & $12.5 \%$ & 0 & $0.0 \%$ & & \\
\hline & Chatting & 6 & $15.0 \%$ & 3 & $7.5 \%$ & & \\
\hline & Facebook & 9 & $22.5 \%$ & 6 & $15.0 \%$ & & \\
\hline & Studying & 0 & $0.0 \%$ & 10 & $25.0 \%$ & & \\
\hline
\end{tabular}

This table showed that there was statistically significant difference in time spent on the internet and type of activity on the internet regarding studied group.

Table (7): Correlation between HAM-A score and HAM-D score as regards age

\begin{tabular}{|c|c|c|c|c|}
\hline \multirow{2}{*}{} & \multicolumn{2}{|c|}{ HAM-A SCORE } & \multicolumn{2}{c|}{ HAM-D SCORE } \\
\cline { 2 - 5 } & $\mathrm{r}$ & $\mathrm{P}$ value & $\mathrm{r}$ & P value \\
\hline HARS SCORE & & & & \\
\hline HAM-D SCORE & 0.435 & 0.005 & & \\
\hline AGE (Years) & 0.318 & 0.046 & -0.011 & 0.945 \\
\hline
\end{tabular}

This table showed that HAM-A score had positive correlation with age and HAM-D score in the patient group.

Table (8): Relation between HAM-A score and HAM-D score as regards sex

\begin{tabular}{|c|c|c|c|c|c|c|}
\hline & \multicolumn{2}{|c|}{ Male } & \multicolumn{2}{c|}{ Female } & \multicolumn{2}{c|}{ Independent t test } \\
\cline { 2 - 7 } & Mean & SD & Mean & SD & t & P value \\
\hline HAM-A score & 17.89 & 3.28 & 19.25 & 2.67 & 1.262 & 0.215 \\
\hline HAM-D score & 19.18 & 3.31 & 21.83 & 5.02 & 1.980 & 0.055 \\
\hline
\end{tabular}

This table showed that there was no statistically significant difference in HAM-A score and HAM-D score regarding sex in patient group.

Table (9): Comparison between genders in regard to severity of depression

\begin{tabular}{|c|c|c|c|c|c|}
\hline \multirow{2}{*}{$\begin{array}{c}\text { Severity of } \\
\text { depression }\end{array}$} & \multicolumn{3}{|c|}{ FREQUENCY } & P \\
\cline { 2 - 5 } & \multicolumn{2}{|c|}{ MALES } & \multicolumn{2}{|c|}{ FEMALES } & \\
\hline MILD & NO & $\%$ & NO & $\%$ & \\
\hline MODERATE & 10 & $76.92 \%$ & 3 & $23.08 \%$ & 0.61 \\
\hline SEVERE & 16 & $80 \%$ & 4 & $20 \%$ & \\
\hline
\end{tabular}

This table showed that there was no statistically significant difference in severity of depression regarding sex in patient group. 
ejhm.journals.ekb.eg

Table (10): Comparison between genders as regard to severity of anxiety

\begin{tabular}{|c|c|c|c|c|c|}
\hline \multirow{2}{*}{$\begin{array}{c}\text { Severity of } \\
\text { anxiety }\end{array}$} & \multicolumn{4}{|c|}{ FREQUENCY } & \multirow{2}{*}{ P } \\
\cline { 2 - 5 } & \multicolumn{2}{|c|}{ MALES } & \multicolumn{2}{|c|}{ FEMALES } & \\
\cline { 2 - 4 } MILD & 12 & $80 \%$ & 3 & $20 \%$ & \multirow{2}{*}{0.33} \\
\hline MODERATE & 16 & $66.67 \%$ & 8 & $33.33 \%$ \\
\hline SEVERE & 0 & $0 \%$ & 1 & $100 \%$ & \\
\hline
\end{tabular}

This table showed that there was no statistically significant difference in severity of anxiety regarding sex in patient group.

Table (11): Risk factors of internet addiction:
1- Male gender (P value 0.478).
2- Family history of excessive internet use (P value 0.001 ).
3- Lack of family control on time spent on the internet by their children (P value 0.001).
4- Internet gaming (P value 0.004).
5- The more the time spent on the internet, the more the chance for internet addiction ( $\mathrm{P}$ value 0.001$)$.
6- Age group: the younger the age, the more the liability for internet addiction ( $\mathrm{P}$ value 0.746 ).
7- Not practicing sports (P value 0.001).
8- Loneliness, lack of self-confidence, \& lack of friends ( $\mathrm{P}$ value 0.001 ).

\section{DISCUSSION}

A major contribution of this study is that it allowed young people to speak in their own voices about a wide range of influences that the internet had in their lives.

Results of the patient group on the proposed internet addiction diagnostic criteria questionnaire showed that $100 \%(n=40)$ of them were proved to be internet addicted. The results of the control group on the same scale showed that $17.5 \%(n=7)$ of them were proved to be internet addicted and $82.5 \%$ $(n=33)$ were proved not to be internet addicted. Our study suggest that the fact that males are more likely to be pathological internet users could be attributed to male's tendency to use internet applications, which are usually associated with problematic behaviors such as online games and chatting rooms.

Busch (18) found same results. He reported that male students are generally more experienced in programming and computer games than females and those male students had more encouragement from parents and friends, in contrast to women who might have been discouraged to use modern technologies. Thus, this study, and several more, demonstrated that male students are more likely to be pathological internet users ${ }^{(19)}$. Griffiths ${ }^{(20)}$ explained this difference by the fact that females are generally more willing than males to discuss emotional issues and problems. Whereas, other studies showed no male-female differences in PIU ${ }^{(21)}$.

Results of the patient group on the Hamilton Anxiety Rating Scale (HAM-A) and the Hamilton Depression Rating Scale (HAM-D) showed that $100 \% \quad(\mathrm{n}=40) \quad$ suffered from psychological
disorders.Our study is in line with many studies which have found that there is a significant association between internet addiction and psychological morbidities as anxiety, stress and depression ${ }^{(22)}$.

On comparison between the patient group \& the control group regarding HAM-A score, 37.5\% $(n=15)$ of the patient group had mild anxiety symptoms, $60 \%(\mathrm{n}=24)$ of the patient group had moderate anxiety symptoms, and $2.5 \%(\mathrm{n}=1)$ of the patient group had severe anxiety symptoms, while $95 \%(\mathrm{n}=38)$ of the control group had no anxiety symptoms, \& $5 \%(n=2)$ of the control group had mild anxiety symptoms. There was statistically significant increase in the patient group in comparison with the control group with HAM-A score $(\mathrm{P}<0.001)$. In regard to social anxiety, our results are in line with past research showing that individuals with high scores in social anxiety scales also had a higher tendency toward IAD ${ }^{(23,24)}$.

On comparison between the patient group \& the control group regarding HAM-D score, $32.5 \%$ $(n=13)$ of the patient group had mild depression, $50 \%(\mathrm{n}=20)$ of the patient group had moderate depression and $17.5 \%(n=7)$ of the patient group had severe depression, while $100 \%(n=40)$ of the control group had no depression, there was statistically significant increase in patient group in comparison with the control group with HAM-D score $(\mathrm{P}<$ 0.001). Our results are consistent with Young (25) who utilized the Zung depression inventory, which suggested that increased levels of depression are associated with PIU. However the ZDI yielded limited clinical utility. Therefore, Young and 
Rodgers ${ }^{(26)}$ used the BDI-II because it is a more psychometrically and clinically valid instrument and they found that PIUs showed increased mild to moderate levels of depression when compared to normal population. Morisson and Gore ${ }^{(27)}$ who utilized the BDI-II as well to measure depressive symptoms in their sample found same results.

Young and Rodgers ${ }^{(26)}$ suggested that low self-esteem, low energy, poor motivation, fear of rejection, feelings of hopelessness and the need for approval associated with depressives contribute to increased internet use. Prior research indicated that the interactive capabilities available on the internet were found to be the most addictive where it is plausible that depressives are drawn to electronic communication because of the anonymous cover granted to them by talking with others through internet, which helps them overcome real-life interpersonal difficulties ${ }^{(29)}$. Therefore, the disappearance of facial expression, voice inflection and eye contact makes electronic communication less threatening, thereby helping the depressive to overcome the initial awkwardness and intimidation in meeting and speaking with others. This anonymous two-way talk also helps depressives feel comfortable sharing ideas with others, thanks to the personal control over the level of their communication, as they have time to plan, contemplate and edit comments before sending an electronic message . However, Young ${ }^{(28)}$ showed that withdrawal from significant real-life relationships is a consequence of PIU. Therefore, the possibility exists that increased levels of social isolation subsequent to excessive time spent in front of a computer may result in increased depression rather than be a cause of such internet overuse.

On comparison between the patient group \& the control group regarding school performance, $37.5 \%(n=15)$ of the patient group and $0 \%$ of the control group had a good as a result, $62.5 \%(n=25)$ of the patient group and $52.5 \%(\mathrm{n}=21)$ of the control group had a very good as a result, $0 \%$ of the patient group and $47.5 \%(n=19)$ of the control group had an excellent as a result. There was statistically significant difference in school performance regarding the patient group $(\mathrm{P}=0.001)$.

On comparison between the patient group \& the control group regarding the family history of excessive internet use, $100 \%(\mathrm{n}=40)$ of the patient group and $17.5 \%(n=7)$ of the control group had a negative family history of excessive internet use, while $82.5 \% \quad(n=33)$ of the control group had a negative family history of excessive internet use, there was statistically significant difference in family history of excessive internet use regarding the patient group $(\mathrm{P}=0.001)$.
On comparison between the patient group \& the control group regarding time spent on the internet, $0 \%$ of the patient group and $82.5 \%(n=33)$ of the control group spent less than 5 hours/day using the internet, $45 \%(n=18)$ of the patient group and $17.5 \%(\mathrm{n}=7)$ of the control group spent 5-7 hours/day using the internet, and $55 \%(n=22)$ of the patient group and $0 \%$ of the control group spent 8 10 hours/day using the internet. There was statistically significant difference in time spent on the internet regarding the studied group $(\mathrm{P}=0.001)$.

Our findings are consistent with the literature discussing pathological internet use where pathological users always surpassed non pathological users in hours spent online per week ${ }^{(\mathbf{2 9} \text {, }}$ 30).

On comparison between the patient group \& the control group regarding the type of activity on the internet, $40 \%(\mathrm{n}=16)$ of the patient group and $35 \%(n=14)$ of the control group used the internet in gaming, $10 \%(\mathrm{n}=4)$ of the patient group and $17.5 \%$ $(n=7)$ of the control group used the internet in watching cartoon, $12.5 \%(\mathrm{n}=5)$ of the patient group and $0 \%$ of the control group used the internet in watching videos, $15 \%(\mathrm{n}=6)$ of the patient group and $7.5 \%(n=3)$ of the control group used the internet in chatting, $22.5 \%(n=9)$ of the patient group and $15 \%$ $(n=6)$ of the control group used the internet in facebooking, and $0 \%$ of the patient group and $25 \%$ $(n=10)$ of the control group used the internet in studying. There was statistically significant difference in type of activity on the internet regarding the studied group $(\mathrm{P}=0.004)$.

Our study showed that males used all online applications more frequent than females. Same finding was reported by DiNicola ${ }^{(31)}$.

On comparison between the school performance of the patient group regarding the time spent on the internet, $45 \%(\mathrm{n}=18)$ of the patient group, who spent 5-7 hours/day using the internet, and $17.5 \%(\mathrm{n}=7)$ of the patient group who spent 8 10 hours/day using the internet, had got a very good as a result, while $37.5 \%(n=15)$ of the patient group, who spent 8-10 hours/day using the internet, had got a good as a result. There was a statistically significant difference in school performance regarding time spent on the internet in the patient group $(\mathrm{P}=0.001)$.

On correlation between HAM-A score and HAM-D score regarding age, results showed that HAM-A score had a positive correlation with age and HAM-D score in the patient group.

Regarding relation between HAM-A score and HAM-D score as regards sex, there was no statistically significant difference in HAM-A score and HAM-D score regarding sex in the patient group $(\mathrm{P}=0.215)$ and $(\mathrm{P}=0.055)$ respectively. 
On comparison between genders regarding severity of depression, $32.5 \%(\mathrm{n}=13)$ of the patient group had mild depression, $76.92 \%(n=10)$ of them were males and $23.08 \%(n=3)$ of them were females. $50 \%(n=20)$ of the patient group had moderate depression, $80 \%(\mathrm{n}=16)$ of them were males and $20 \%(n=4)$ of them were females and $17.5 \%(n=7)$ of the patient group had severe depression, $28.57 \%$ of them were males and $71.43 \%(n=5)$ of them were females. There was no statistically significant difference in severity of depression regarding sex in the patient group $(\mathrm{P}=0.610)$.

On Comparison between genders regarding severity of anxiety, $37.5 \% \quad(n=15)$ of the patient group had mild anxiety symptoms, $80 \%$ of them were males and $20 \%(\mathrm{n}=3)$ were females. $60 \%$ $(n=24)$ of the patient group had moderate anxiety symptoms, $66.67 \%(n=16)$ of them were males and $33.33(n=8)$ of them were females, and $2.5 \%(n=1)$ of the patient group had severe anxiety symptoms, $0 \%$ of them were males and $100 \%(n=1)$ of them were females. There was no statistically significant difference in severity of anxiety regarding sex in patient group $(\mathrm{P}=0.330)$.

From our study, the risk factors of internet addiction showed that male gender is more liable for internet addiction than female gender due to more use of internet applications by males. Family history of excessive internet use is strongly associated with internet addiction as parents are the models for their children. Lack of family control on time spent on the internet by their children encourages their children to spend more and more time on the internet and internet gaming. The more the time spent on the internet, the more the chance for internet addiction. Regarding age group, the younger the age, the more the liability for internet addiction. Children who are not practicing sports or having other hobbies have plenty of spare time, which is spent on the internet, and loneliness. Lack of self-confidence \& lack of friends pushes the children to find friends in the virtual world.

\section{CONCLUSIONS}

No doubt that the internet is very important in our life. According to our study:

- There was a strong association between positive family history of excessive internet use and the internet addiction among children of those families.

- There was a significant association between internet addiction and depression and anxiety.

- In the study group, mild and moderate anxiety and depression were more common in males than in females, while severe anxiety and depression were more common in females than in males.

- School performance of the study group was strongly affected by the internet addiction.

\section{RECOMMENDATIONS}

\section{From results of this study we can recommend:}

1. Large-scale researches and studies on internet addiction should be conducted to find out the real numbers of children who are affected by internet addiction and to learn about the negative effects of Internet addiction.

2. Awareness seminars for parents and children should be held at schools to highlight the dangers and negative impacts of internet addiction.

3. We should direct our children to practice sports in the sports clubs \& to read stories or books in the libraries.

4. Our children must be engaged in group play to develop their mental and physical abilities.

5. Parents should encourage the good uses of the internet e.g. studying or researching should be highlighted.

6. Control of the child s use of the internet by setting rules to limit the internet use.

7. Parents should set an internet-free day.

8. Before 6 years of age the smart devices (phones, tabs, computers, etc......) must not be available for use.

9. Regular periodic visits to social specialists at the school for early detection of internet addiction cases and referral of the detected cases to neuro-psychiatrists as early treatment gives excellent results.

10. Mass media campaigns must be adopted to reduce the risk of internet addiction.

11. For internet addicted children, gradual withdrawal with gradual replacement with other physical \& mental activities should be done.

12. Parents should be a good role model and spend more time with their children.

\section{REFERENCES}

1. Christakis D (2010): Internet addiction: A 21st century epidemic? Bio Med Central Medicine, 8: 61-6.

2. Potenza MN (2006): Should addictive disorders include non-substance-related conditions? Addiction, 101 (1): 142-151.

3. Goldberg I (1996): Internet Addictive Disorder (IAD) diagnostic criteria. //www.webcitation.org/query?url=http\%3A\%2F\%2 $\mathrm{Fw}$ ww. psycom. net \%2Fiadcriteria.html\&date $=2013 / 02 / 06$.

4. Black DW, Belsare G, Schlosser S (1999): Clinical features, psychiatric comorbidity, and health related quality of life in persons reporting compulsive computer 
use behavior. Journal of Clinical Psychiatry, 60 (12): 839-844.

5. Ko CH, Yen JY, Chen CC et al. (2005): Proposed diagnostic criteria of Internet addiction for adolescents. Journal of Nervous and Mental Disease, 193 (11): 728733.

6. Young KS (1998): Internet addiction: the emergence of a new clinical disorder. Cyber Psychol. Behav., 1: 237244.

7. Beard KW, Wolf EM (2001): Modification in the proposed diagnostic criteria for Internet addiction. Cyberpsychology \& Behavior, 4: 377-383.

8. Young KS (1998): Caught in the Net: How to Recognize the Signs of Internet Addiction and a Winning Strategy for Recovery. NewYork: John Wiley \& Sons, Pp: 1-256.

9. Chak K, Leung L (2004): Shyness and locus of control as predictors of Internet addiction and Internet use. Cyberpsychol. Behav.,7: 559-570.

10. Wan CS, Chiou WB (2006): Why are adolescents addicted to online gaming? An interview study in Taiwanl, Cyber Psychology \& Behavior, 9 (6): 762-6.

11. Deci EL, Ryan RM (2000): The what and why of goal pursuits: human needs and the self-determination of behavior. Psychol Inq., 11: 227-268.

12. Cao FL, Su LY, Gao XP (2007): Control study of group psychotherapy on middle school students with Internet overuse. Chinese Mental Health Journal, 21 (5): 346-9.

13.Abd El-Hameed RA, Mohammed NA, Aly HY (2017): Internet addiction among medical students of Sohag University, Egypt. Journal of the Egyptian public health Association, 92 (2): 86-95.

14. Abdelghani M, Salah El-Deen G, Said M et al. (2018): Determinants of internet addiction in a sample of Egyptian university students: A survey. Journal of Internet Addiction Review, 2 (1): 30-34.

15. Voiskunskiy AE (2000): The phenomenon of dependence on the Internet. Humanitarian Studies of the Internet. In A.E. Voiskunskiy (Eds.): Moscow: MojaiskTerra, Pp: 110-131.

16. Hamilton M (1959): The assessment of anxiety states by rating. Br J Med Psychol., 32: 50 - 55.

17.Hamilton M (1960): A rating scale for depression. Journal of Neurology, Neurosurgery, and Psychiatry, 23: 56-62.

18. Busch T (1995): Gender differences in self-efficacy and attitudes towards computers. Journal of Educational Computing Research, 12: 147-158.

19. Widyanto L, Griffiths $M$ (2006): Internet addiction: A Critical Review. International Journal of Mental Health and Addiction, 4 (1): 31-3.
20.Griffiths M (1998): Internet addiction: Does it really exist? In J. Gackenbach (Ed.), Psychology and the internet: Intrapersonal, interpersonal and transpersonal applications: New York: Academic Press. Pp: 61-75.

21. Chou C, Condron L, Belland JC (2005): A review of the research on internet addiction. Educational Psychology Review, 17: 363-388.

22. Seifi A, Ayati M, Fadaei M (2014): The study of the relationship between internet addiction and depression, anxiety and stress among students of Islamic Azad University of Birjand. Int $\mathbf{J}$ Econ Manage Soc Sci., 3: 28-32.

23.Prizant-Passal S, Shechner T, Aderka IM (2016): Social anxiety and Internet use-A meta-analysis: What do we know? What are we missing? Comput. Hum. Behav., 62: 221-229.

24. Enez Darcin A, Kose S, Noyan CO et al. (2016): Smartphone addiction and its relationship with social anxiety and loneliness. Behav Inform Technol, 35: 520 5.

25. Young KS (1997): What makes the Internet addictive: Potential explanations for pathological Internet use Paper presented at the the 105th annual conference of the American Psychological Association, Chicago, IL. https://www.healthyplace.com/ addictions/center-forinternet-addiction-recovery/what-makes-the-internetaddictive-potencial.

26. Young KS, Rogers RC (1998): The relationship between depression and Internet addiction. Cyberpsychology and Behavior, 1: 25-28.

27. Morrison CM, Gore H (2010): The relationship between excessive Internet use and depression: A questionnaire-based study of 1,319 young people and adults. Psychopathology, 43 (2): 2121-126.

28. Young KS (1996): Internet addiction: the emergence of a new clinical disorder. Cyberpsychology and Behavior, 1 (3): 237-244.

29. Chen SH, Chou C (1999): Development of Chinese Internet addiction scale in Taiwan. Poster presented at the 107th American Psychology Annual convention, Boston, USA. https://www. tandfonline.com/doi/full/ 10.1080/02673843.2019.1674165

30. Chou C, Hsiao M (2000): Internet addiction, usage, gratification, and pleasure experience: the Taiwan college students' case. Computers \& Education, 35 (1): 65-80.

31.DiNicola MD (2004): Pathological Internet use among college students: The prevalence of pathological Internet use and its correlates. Dissertation Abstracts International, 65 (05): 149-156. 